\title{
PERAN KELUARGA DALAM MENCEGAH BAHAYA ATAU ADVERSE EVENT TERHADAP PASIEN
}

\author{
Audina Tio Junianti Manik \\ audina.junianti@gmail.com
}

\section{Latar Belakang}

Keselamatan pasien (patient safety) adalah suatu sistem upaya di rumah sakit atau instansi kesehatan manapun agar pasien tercegah dari cidera yang disebabkan oleh kesalahan (adverse event) atau bahaya. Perawatan rawat inap memiliki peran penting dalam pelayanan perawatan untuk observasi, diagnosis, pengobatan atau upaya perawatan kesehatan lainnya, begitu juga dalam menjalankan patient safety.

Tujuan sistim keselamatan pasien adalah sebagai berikut: a) Menciptakan budaya keselamatan pasien di rumah sakit,

b) Meningkatkan akuntabilitas rumah sakit terhadap pasien dan masyarakat,

c) Menurunkan kejadian tidak diharapkan (KTD) di rumah sakit, d) Melakukan pencegahan sehingga tidak akan terjadi kejadian yang tidak diharapkan ${ }^{10}$. Ada berbagai kelompok jenis insiden akibat dari bahaya atau adverse event,

1. Kejadian tidak diharapkan (KTD)
Suatu kejadian yang mengakibatkan cedera yang tidak diharapkan pada pasien karena suatu tindakan atau karena tidak bertindak, bukan karena underlying disease atau kondisi pasien.

2. Kejadian nyaris cedera (KNC) Suatu Insiden yang belum sampai terpapar ke pasien sehingga tidak menyebabkan cedera pada pasien.

3. Kejadian tidak cedera (KTC) Insiden yang sudah terpapar ke pasien, tetapi tidak menimbulkan cedera, dapat terjadi karena keberuntungan.

4. Kondisi potensial cedera (KPC) Kondisi yang sangat berpotensi untuk menimbulkan cedera, tetapi belum terjadi insiden.

5. Kejadian sentinel Suatu KTD yang mengakibatkan kematian atau cedera yang serius. ${ }^{10}$

Tetapi bahaya atai adverse event yang kemungkinan terjadi bukan 
hanya sepenuhnya tugas dari seorang perawat, tetapi keluarga juga

berperan penting dalam mencegah terjadinya bahaya atau adverse event pada pasien. Keluarga cenderung menjadi pemicu masalah penyakit anggotanya dan sekaligus menjadi pelaku dalam menentukan masalah penyakitnya (Friedman, 2010).

Terdapat lima tugas kesehatan keluarga sebagai bagian dari fungsi keluarga dalam perawatan kesehatan antara lain; keluarga mampu mengenali permasalahan yang ada, mampu mengambil keputusan tindakan kesehatan yang tepat, mampu merawat anggota keluarga yang sakit, mampu memelihara kesehatan lingkungan, dan mampu menggunakan fasilitas kesehatan yang tersedia (Basavanthappa 2008).

Oleh karena itu, penulis akan membahas mengenai peran keluarga dalam mencegah bahaya atau adverse event pada pasien.

\section{Metode}

Penulisan ini penulis buat dengan model literature riview dengan membaca dan menganalisis serta membandingkan beberapa berbagai sumber online dengan rentang batasan waktu 2012 sampai tahun 2020. Dalam pencarian, penulis mendapatkan sepuluh jurnal online yang sesuai dengan topik.

Dan juga penulis mengambil dua jurnal sebagai bahan analisa penlis. Jurnal yang pertama berjudul 'BentukBentuk Dukungan Keluarga Terhadap Ibu dengan HIV Positif dalam Kepatuhan Terapi ARV di Kota Semarang' oleh Nurina Dyah Larasaty, Zahroh Shaluhiyah, dan Antono Suryoputro. Jenis penelitian ini adalah penelitian deskriptif dengan pendekatan kualitatif. Instrumen yang digunakan dalam penelitian adalah peneliti sendiri dengan pedoman wawancara yang berisi pertanyaan-pertanyaan terbuka yang berhubungan dengan informan, sehingga pelaksanaan pengumpulan data dapat berlangsung efisien. Pengolahan data dengan menggunakan langkah-langkah analisis data kualitatif yang meliputi : transcribing, reduksi data, penyajian data, dan kesimpulan.

Jurnal kedua yang penulis ambil berjudul 'Analisa Peran keluarga Sebagai Pengawas Minum Obat (PMO) Pasien TB Paru' oleh Wiwit Febrina dan Amila Rahmi. Jenis penelitian ini adalah penelitian kualitatif dengan pendekatan fenomenologi yang 
dilakukan di Puskesmas Ophir. Penelitian ini dilakukan dengan wawancara mendalam terhadap partisipan untuk mengeksplor peran keluarga sebagai Pengawas Minum Obat (PMO). Partisipan diambil secara purposive sampling berjumlah 8 orang terdiri dari 3 orang PMO, 3 Orang Pasien TB Paru, 1 Orang petugas TB Paru Puskesmas, 1 Orang Kepala Puskesmas.

\section{Hasil}

Dari jurnal yang pertama diperoleh hasil umur informan paling muda adalah 26 tahun dan paling tua adalah 53 tahun. Sembilan informan memiliki latar belakang pendidikan yang rendah yaitu tamat $\mathrm{SD}$, SLTP dan SMA dan satu orang yang tidak pernah mengenyam bangku sekolah. Hanya satu informan yang memiliki latar pendidikan yang cukup tinggi yaitu sebagai sarjana. Semua informan membuka status HIV positifnya kepada keluarga. Empat suami informan yang masih hidup mengaku merasa bersalah atas perbuatannya, yang mengakibatkan informan tertular HIV. Sedangkan dua informan yang memiliki orang tua yang masih hidup mengaku kaget dan tidak percaya dengan status HIV positif anak mereka. Namun demikian, satu informan memilih untuk tidak membuka status kepada orang tuanya dengan pertimbangan tidak ingin membebani orang tua mereka. Lima informan menuturkan bahwa tanggapan anak informan ketika mengetahui status HIV positif informan adalah sedih dan tidak percaya.

Dari jurnal kedua diperoleh hasil partisipan pada penelitian ini berjumlah 8 orang yang terdiri dari 3 orang PMO, 3 Orang Pasien TB Paru, 1 Orang Pemegang Program TB Paru Puskesmas Ophir, dan 1 Orang Kepala Puskesmas Ophir, Kec. Luhak Nan Duo Kab. Pasaman Barat. Hal ini dimaksudkan agar informasi yang diperoleh sesuai dengan tujuan penelitian yang peneliti lakukan. Adapun berdasarkan hasil penelitian, peran keluarga sebagai motivator sudah optimal, peran mengingatkan pemeriksaan ulang sputum sudah optimal, peran pengawasan pengobatan sudah optimal dilakukan oleh keluarga, dan peran keluarga dalam memberi edukasi pasien TB Paru belum maksimal.

Dari hasil yang diperoleh diatas, dapat disimpulkan bahwa keluarga juga mengambil peran dalam kesembuhan dan keselamatan pasien, apalagi jika si pasien tidak dalam pantauan perawat. Keluarga bisa mencegah keadaan pasien lebih parah, seperti salah satunya adalah dalam mengawasi pasien dalam minum obat, jika si 
pasien tidak diawasi dan tidak memiliki

kesadaran, keluarga berperan dalam

mengawasinya.

\section{Pembahasan}

Dilihat dari beberapa kasus, keluarga memiliki peran dalam mencegah terjadinya bshsys kepada pasien. Peran orang tua merupakan penanganan yang dilakukan oleh ibu ataupun anggota keluarga yang lain. Keluarga merupakan unit terkecil dari masyarakat yang berkumpul dan tinggal dalam suatu rumah tangga, satu dengan yang lainnya saling bergantung dan berinteraksi, bila salah satu atau beberapa anggota keluarga yang mempunyai kesehatan kurang baik, maka akan memengaruhi anggota keluarga yang lain (Riska,2016). Sebagai komponen yang tidak terpisahkan dari masyarakat, keluarga memiliki peran signifikan dalam status kesehatan. Keluarga berperan terhadap optimalisasi pertumbuhan, perkembangan, dan produktivitas seluruh anggotanya melalui pemenuhan kebutuhan gizi dan menjamin kesehatan anggota keluarga. Menurut Hermawati (2015), kejelasan terhadap perilaku dan pengetahuan yang didapat tentang apa yang seharusnya dilakukan (peran). Maka jika pengetahuan / perilaku sudah pasti, seseorang dapat menjalankan peran dengan maksimal.
Menurut Mubarok (2007), pemberian perawatan secara fisik merupakan beban yang paling berat dirasakan keluarga. Keluarga juga berperan memberikan motivasi atau dorongan agar pasien termotivasi untuk menjalani pengobatan sesuai aturan hingga sembuh. Bentuk peran yang diberikan adalah berupa dukungan moral dan harapan kesembuhan bagi pasien. Secara psikologis, kedekatan batin antara anggota keluarga menjadikan dukungan berupa harapan kesembuhan dan keinginan keluarga untuk melihat pasien dapat beraktifitas kembali menjadikan motivasi kepada pasien. Di dalam kasus TB Paru, Peran keluarga sangatlah penting dalam pemeriksaan ulang sputum, karena hal inilah dapat menentukan sejauh mana keberhasilan pengobatan bagi

pasien TB paru. Mengingatkan pemeriksaan ulang sputum dilakukan agar adanya ketepatan jadwal pemeriksaan ulang oleh pasien TB Paru. Peran mengingatkan pemeriksaan ulang juga dilakukan dengan mengantarkan sputum untuk pemeriksaan jika pasien tidak mampu mengantar pada jadwal pemeriksaan.

Keluarga juga berperan dalam mengawasi pengobatan pasien, guna mewujudkan medication safety, sehingga keluarga 
mengambil peran yaitu Pengawas Minum Obata tau yang disingkat PMO. Keinginan kesembuhan bagi pasien terlihat dari kemauan PMO untuk memotivasi pasien agar tidak jenuh dan putus asa selama proses pengobatan. Lamanya proses pengobatan, dan pengobatan yang harus teratur, serta adanya efek samping obat dan keluhan kesehatan bagi pasien, mengharuskan adanya peran aktif dari keluarga, terutama dalam memotivasi pasien. Pasien akan termotivasi untuk berobat secara teratur disaat pasien dan PMO samasama mengharapkan kesembuhan pasien. Peran keluarga dalam mengawasi pengobatan pasien tidaka hanya mengawasi keteraturan minum obat bagi pasien, tetapi juga mengawasi ketersediaan obat di rumah pasien. Dalam beberapa penyakit, efek samping obat dapat mengganggu pasien untuk teratur menelan obat. Keluarga adalah yang pertama mengetahui efek samping obat. Seperti sebagian efek samping obat yang dirasakan oleh pasien TB atau kanker mungkin adalah seperti pusing, mual, muntah-muntah, gatal-gatal, dan lain-lain, biasanya disampaikan oleh pasien kepada PMO untuk dikonsultasikan ke petugas kesehatan. Sehingga dukungan dari keluarga dapat meningkatkan kepatuhan pasien dalam berobat. Faktor-faktor yang mempengaruhi kepatuhan berobat dipandang dari sisi biopsikososial adalah :1). Karakteristik penyakit (lamanya infeksi diterapi dan keparahan dan stadium penyakit); 2). Karakteristik terapi (lamanya terapi, kesulitan fisik untuk minum obat, keparahan dan lamanya efek samping, rutinitas sehari-hari dan pembatasan diet, kompleksitas jadwal dosis); 3).Karakteristik klien (sikap, sistem keyakinan, kepribadian/perilaku, motivasi, psikologis); 4). Gaya hidup tak stabil (waktu bekerja, suasana sekitar dan kesehatan mental klien).

Selain itu, Salah satu bentuk dukungan sosial menurut Kaplan adalah dukungan emosi. Dukungan Emosi (Emotional Support), seperti ekspresi cinta, empati dan perhatian. Menurut Witty et al. (1992) dalam Conger et al. (1994), individu dapat mencurahkan perasaan, kesedihan ataupun kekecewaannya pada seseorang, yang membuat individu sebagai penerima dukungan sosial merasa adanya keterikatan, kedekatan dengan pemberi dukungan, sehingga menimbulkan rasa aman dan percaya.(Nasronudin, 2007) Dukungan ini lebih berfungsi saat menghadapi kejadian stres yang tidak dapat dikontrol, dan dapat untuk mengurangi emosi negatif yang muncul saat individu mengalami stres.(Graeff, 1996). Suprajitno (2004) 
menyatakan bahwa fungsi pemeliharaan kesehatan, keluarga mempunyai tugas di bidang kesehatan yang perlu dipahami dan dilakukan, meliputi: mengenal masalah kesahatan keluarga, memutuskan tindakan kesehatan yang tepat bagi keluarga, merawat keluarga yang mengalami gangguan kesehatan (Salah satunya dukungan keluarga di sini adalah dengan mengantar informan ke klinik VCT) memodifikasi lingkungan keluarga untuk menjamin kesehatan keluarga, dan memanfaatkan fasilitas pelayanan kesehatan disekitarnya bagi keluarga.(Sherr, 2008). . Kemampuan keluarga yang baik dalam melaksanakan lima tugas kesehatan keluarga dapat menjadikan keluarga sebagai pemberi perawatan yang efektif bagi anggota keluarga yang sakit (Friedman et al. 2003). Keluarga yang dapat menjalankan fungsi perawatan kesehatan untuk keluarga yang sakit dapat membantu anggota keluarga yang sakit mencapai kondisi yang lebih baik secara fisik maupun psikologis.

Keluarga juga diharapkan menjadi educator yang baik bagi pasien. Tetapi tidak semua keluarga yang memiliki atau mendapatkan edukasi (pengetahuan) yang cukup agar keluarga lebih siaga menghadapi tanda bahaya pada pasien. Efendi \& Makhfudli (2013) mengemukakan bahwa sebagai pendidik dan pelaksana konseling keperawatan perawat melaksanakan fungsi sebagai memberikan informasi kepada pasien. Melaksanakan penyuluhan atau pendidikan kesehatan untuk pemulihan kesehatan klien antara lain tentang pengobatan, hygiene, perawatan, serta gejala dan tanda-tanda bahaya. Untuk contohnya kebiasaan meminum obat setelah sarapan merupakan gambaran kekurang pahaman akan aturan pengobatan. Hal ini mengidentifikasi bahwa pemahaman keluarga belum optimal dan msih perlu pemberian informasi secara berkesinambungan serta adanya monitoring dan evaluasi dari instansi kesehatan. Oleh karena itu, Edukasi dan keterlibatan pada keluarga penting untuk diberikan oleh setiap petugas kesehatan sehingga keluarga mampu merawat pasien sesuai kebutuhan (Friedman et al. 2003). Edukasi yang diberikan kepada pasien dan keluarganya dilakukan guna memenuhi hak pasien, karena pasien dan keluarga mempunyai hak untuk mendapatkan informasi tentang rencana dan hasil pelayanan termasuk kemungkinan terjadinya KTD. Karena itu, di rumah sakit harus ada sistem dan mekanisme mendidik pasien dan keluarganya tentang kewajiban dan tanggung jawab pasien dalam asuhan 
keperawatan. Dengan pendidikan tersebut diharapkan pasien dan keluarga dapat: a) Memberikan info yang benar, jelas, lengkap dan jujur, b) Mengetahui kewajiban dan tanggung jawab, c) Mengajukan pertanyaan untuk hal yang tidak dimengerti, d) Memahami dan menerima konsekuensi pelayanan, e) Mematuhi instruksi dan menghormati peraturan rumah sakit, f) Memperlihatkan sikap menghormati dan tenggang rasa, g) Memenuhi kewajiban finansial yang disepakati.

\section{Penutup}

Keluarga memiliki peran penting dalam memberikan asuhan keperawatan mandiri yang dilakukan oleh pasien, seperti menjadi Pengawas Minum Obat (PMO), memberikan dukungan sosial, salah satunya adalah dukungan emosi seperti ekspresi cinta, empati dan perhatian. Jika pasien mendapatkan dukungan tersebut, maka pasien akan lebih menurut dalam menjalankan pengobatannya. Keluarga berperan dalam pemberian asuhan keperawatan ini juga bertujuan untuk mencegah bahaya pada pasien, contohnya jika pasien mulai merasakan tanda-tanda bahaya penyakit yang dideritanya dan si pasien tidak bisa mengungkapkannya, maka disinilah peran keluarga dalam mengawasi pasien dan segera membawanya atau melaporkan keadan si pasien kepada pihak tenaga kesehatan.

Oleh karena itu, dibutuhkannya pengetahuan keluarga mengenai penyakit dan hal-hal yang berkaitan dengan penyakit pasien guna mencegah kondisi pasien yang lebih parah. Diharapkan juga kepada perawat atau petugas kessehatan agar memberikan edukasi ke pada keluarga ataupun pasien agar mereka mendapatkan informasi yang lebih, dan pemberian asauhan keperawatanpun dapat berjalan dengan baik.

\section{Daftar Pustaka}

Asmiarti, R. M., Hayati, F., Ishariani, L. 2018. Peran Keluarga dalam Pencegahan Stroke pada Pasien Hipertensi di Puskesmas Bendo Kecamatan Pare Kabupaten Kediri. Jurnal ILKES (Jurnal Ilmu Kesehatan), 9(1), 12-20.

(http://ilkeskh.org/index.php/ilkes/article/do wnload/65/47/)

Dary, Puspita, D., Luhukay, J. F. 2018. Peran Keluarga Dalam Penanganan Anak dengan Penyakit ISPA Di RSUD Piru. Jurnal Keperawatan Muhammadiyah, 3(1), 35-49. (http://journal.umsurabaya.ac.id/index.php/JKM/article/downl oad/1469/1360) 
Febrina, W., Rahmi, A. 2018. Analisis Peran Keluarga sebagai Pengawas Minum Obat (PMO) Pasien TB Paru. Jurnal Human Care, 3(2), 118-129.

(https://ojs.fdk.ac.id/index.php/humancare/ar $\underline{\text { ticle/view/66/pdf) }}$

Herawati, Y. T. 2015. Budaya Keselamatan Pasien di Ruang Rawat Inap Rumah Sakit X Kabupaten Jember. Jurnal IKESMA, 11(1), 52-60.

(https://jurnal.unej.ac.id/index.php/IKESMA /article/view/4350/3288)

Kudri, A. M., Barliana, M. I. 2018.

Pengetahuan dan Kesadaran Apoteker dan Pasien dalam Melaporkan Adverse Drug Reaction (ADR) terhadap Keamanan Obat. FarmakaSuplemen, 16(2), 525-530. (http://journal.unpad.ac.id/farmaka/article/vi ew/17602/pdf)

Kusumaningrum, T., Pradanie, R., Yunitasari, E., Kinanti, S. 2016. Peran Keluarga dan Kualitas Hidup Pasien Kanker Serviks. Jurnal Ners, 11(1), 112-117. (https://ejournal.unair.ac.id/JNERS/article/view/1920 Ipdf_13)

Larasaty, D. N., Shaluhiyah, Z., Suryoputro, A. 2015. Bentuk-Bentuk Dukungan Keluarga Terhadap Ibu dengan HIV Positif dalam Kepatuhan Terapi ARV di Kota Semarang. Jurnal Promosi Kesehatan Indonesia, 10(2), 116-130.

(https://ejournal.undip.ac.id/index.php/jpki/a $\underline{\text { rticle/download/18971/13231) }}$

Mukharrim, M. S., Ahri, R. A., Yusriani. 2019. Pelaksanaan Program Perencanaan Persalinan Dan Pencegahan Komplikasi (P4K) Melalui Peran Keluarga Di Kabupaten Gowa. Jurnal Ilmiah Kesehatan, 18(2), 49-58.

(http://journals.stikim.ac.id/index.php/jikes/a $\underline{\text { rticle/view/222/271) }}$

Puspita, E., Oktaviarini, E., Santik, Y. D. P. 2017. Peran Keluarga dan Petugas Kesehatan dalam Kepatuhan Pengobatan Penderita Hipertensi di Puskesmas Gunungpati Kota Semarang. Jurnal Kesehatan Masy.Indonesia, 12(2), 25-32. (https://jurnal.unimus.ac.id/index.php/jkmi/a $\underline{\text { rticle/download/3172/3056) }}$

Salawati, L. 2020. PENERAPAN KESELAMATAN PASIEN RUMAH SAKIT. Jurnal Averrous, 6(1), 98-107. (https://ojs.unimal.ac.id/index.php/averrous/ article/download/2665/1651)

Simamora, R. H. (2019). Buku ajar pelaksanaan identifikasi pasien. Uwais Inspirasi Indonesia. 